Research Paper

\title{
Effects of Photodynamic Therapy Using Yellow LED-light with Concomitant Hypocrellin B on Apoptotic Signaling in Keloid Fibroblasts
}

\author{
Yongqing $\mathrm{Hu}^{1 *}$, Chunmin Zhang1*, Shengli $\mathrm{Li}^{2}$, Ya Jiao ${ }^{3}$, Tonggang $\mathrm{Qi}^{4}$, Guo Wei ${ }^{1}$, Gangwen Han ${ }^{1,5 凶}$ \\ 1. Department of Dermatology, the Second Hospital of Shandong University, Jinan 250033, Shandong, China. \\ 2. Department of Hematology, the Second Hospital of Shandong University, Jinan 250033, Shandong, China. \\ 3. Department of Plastic Surgery, the Second Hospital of Shandong University, Jinan 250033, Shandong, China. \\ 4. Central Research Laboratory, the Second Hospital of Shandong University, Jinan 250033, Shandong, China. \\ 5. Department of Dermatology, Peking University International Hospital, Beijing 102206, China. \\ * These authors contributed equally to this work. \\ $\triangle$ Corresponding author: Gangwen Han, Department of Dermatology, Peking University International Hospital, Life Park Road No.1, Life Science Park of \\ Zhong Guancun, Changping District, Beijing 102206, China. Phone: (+86 10) 6900 6487; E-mail: hangangwen@pkuih.edu.cn. \\ (c) Ivyspring International Publisher. This is an open access article distributed under the terms of the Creative Commons Attribution (CC BY-NC) license \\ (https://creativecommons.org/licenses/by-nc/4.0/). See http://ivyspring.com/terms for full terms and conditions.
}

Received: 2016.10.14; Accepted: 2016.11.21; Published: 2017.02.25

\begin{abstract}
Keloid is a common and refractory disease characterized by abnormal fibroblast proliferation and excessive deposition of extracellular matrix components. Hypocrellin B (HB) is a natural perylene quinone photosensitizer. In this experiment, we studied the effects of photodynamic therapy (PDT) using yellow light from light-emitting diode (LED) combined with HB on keloid fibroblasts (KFB) in vitro. Our results showed that HB-LED PDT treatment induced significant KFB apoptosis and decreased KFB cell viability. HB-LED PDT treatment lead to significant $B A X$ upregulation and BCL-2 downregulation in KFB cells, which led to elevation of intracellular free $\mathrm{Ca}^{2+}$ and activation of caspase-3. Our data provides preliminary evidence for the potential of HB-LED PDT as a therapeutic strategy for keloid.
\end{abstract}

Key words: keloid fibroblasts; Hypocrellin B; photodynamic therapy; apoptosis

\section{Introduction}

Keloid is a refractory disease commonly seen in dermatology and cosmetic surgery. Keloid fibroblasts (KFB), the most critical cells in keloid tissue formation, proliferate abnormally and secrete excessive extracellular matrix in a fashion similar to benign tumors $[1,2]$. The current standard of care for keloid includes local injections of glucocorticoids, compression, external use of silica gel and tretinoin, is unsatisfactory. Additionally, removal of keloid with surgical resection alone has recurrence rates of $45-100 \%$ [3]. Excision with early postoperative radiotherapy is relatively effective compared to other treatment options, but possible risk of radiation for children and young adult limits its use clinically [4]. Therefore, further study of the pathogenesis and development of novel therapeutic strategies for keloid are requisite.
Hypocrellin, a perylene quinone derivative, was isolated from Hypcrella bambusae Sacc (Hypocreaceae, Ascomycetes) [5]. Hypocrellin has the advantages of high quantum yields of singlet oxygen, strong photogeneration of anion radicals in deoxygenated media, low dark toxicity, quick clearance from normal tissue and availability in a pure, monomeric form, and therefore hypocrellin has been widely used in photodynamic therapy as a photosensitizer [5-9]. Hypocrellin mainly consists hypocrellin A (HA) and hypocrellin B (HB). HA and $\mathrm{HB}$ are similar in structure with the difference in one hydroxyl group. Photodynamic therapy with HB or $\mathrm{HB}$ derivatives has been shown to have antitumor activity through induction of tumor cell apoptosis and inhibition of cell viability from several studies $[6,7,9]$. Since keloid shares certain features of tumors with 
abnormal cell proliferation, we studied the effects of photodynamic therapy on apoptosis and apoptotic signal molecules in KFB cells by combining yellow LED-light with HB (HB-LED PDT). Our goal was to provide evidence for HB-LED PDT as a potential clinical therapeutic method for treatment of keloid.

\section{Materials and methods}

\section{Reagents and apparatus}

HB was from Abcam Biochemicals (USA). FITC-conjugated anti-BAX, PE-conjugated anti-BCL-2, FITC-conjugated mouse IgG1 and PE-conjugated mouse IgG1 were obtained from BioLegend (Pacific Heights Blvd, San Diego, CA). AnnexinV-FITC (AV) and propidium iodide (PI) were from BD Bioscience (USA). Caspase-3 activity kit was from Beyotime (Haimen, China). Reverse transcription kit was from Takara (Dalian, China). LightCycler ${ }^{\circledR} 480$ SYBR Green I Master mix was from Roche (USA). Fluo-3/ AM was from Beyotime (Haimen, China). Microplate reader was from Thermo (Thermo Fisher Scientific Inc, Shanghai, China). Real-time fluorescence quantitative PCR (Mastercycler ${ }^{\circledR}$ epRealplex) was from Eppendorf (German). Flow cytometer was from BD Bioscience (San Jose, CA). LSM 710 Confocal Laser-Scanning Microscope was from Zeiss (Carl Zeiss AG, Germany). LED-IA photodynamic therapy apparatus was from Wuhan Yage Optic and Electronic Technique Co. Ltd (China).

\section{Light source selection and irradiation method}

Considering the HB absorption (Supplementary Fig. 1) and skin penetration of visible light, yellow light was selected from LED-IA photodynamic therapy apparatus. The irradiation intensity of our LED therapeutic apparatus is $4 \mathrm{~mW} / \mathrm{cm}^{2}$. The irradiation dose of $3 \mathrm{~J} / \mathrm{cm}^{2}$ was chosen based on preliminary experiments. We irradiated cells by directly exposing the culture plate to the LED-light outside of the incubator, while non-irradiated cells covered with aluminum foil were also placed outside of incubator for an equivalent time. The effect of the culture plate lid on irradiation intensity was removed according to the manufacturer's protocol. Irradiation dosage $=$ irradiation intensity $\times$ time $($ second).

\section{Cells isolation and culture}

Primary human keloid fibroblasts were isolated from keloid tissues of a female patient. Informed consent for using tissue in cell culture was obtained. This study was approved by the human ethical committee of the Second Hospital of Shandong University. The cells were cultured in DMEM media supplemented with $10 \%(\mathrm{v} / \mathrm{v})$ heat-inactivated fetal bovine serum (Clark, Australian), at $37^{\circ} \mathrm{C}$ in a humidified $5 \% \mathrm{CO}_{2}$ incubator. Cells from 3 to 6 passages were used.

\section{Hypocrellin B concentration determination by ${ }^{\prime C} C_{50}$}

To test the phototoxicity of $\mathrm{HB}$, the cells treated with $\mathrm{HB}$ at the concentration of $10^{-5}, 10^{-6}, 10^{-7}, 10^{-8}, 10^{-9}$ and $10^{-10} \mathrm{~mol} / \mathrm{L}$ were exposed to $3 \mathrm{~J} / \mathrm{cm}^{2}$ of LED yellow light. Cell viability was tested by MTT assay. The modified Karber's method was used to calculate $\mathrm{IC}_{50}$. $\mathrm{IC}_{50}$ (50\% inhibiting concentration) of $\mathrm{HB}$ was $3.3252 \times 10^{-7} \mathrm{~mol} / \mathrm{L}$ at $12 \mathrm{~h}$ after irradiation. $1 \times 10^{-7}$ $\mathrm{mol} / \mathrm{L} \mathrm{HB}$ was chosen to explore the effect of HB-LED PDT on apoptosis of KFB in vitro. In view of the photosensitivity of $\mathrm{HB}$, particular attention was paid to avoid light exposure during whole experiments.

\section{Modified MTT cell viability assay}

Cells were divided into 4 groups including DMEM medium only (negative control, NC), HB only, LED only and HB + LED exposure (HB-LED PDT). Modified MTT assay was performed as previous publication [10]. Cells at $7 \times 10^{3} /$ well were seeded in four 96 -well plates and cultured for $12 \mathrm{~h}$. The culture medium was replaced with fresh DMEM medium with or without HB and continually cultured for $3 \mathrm{~h}$. The media were changed to PBS and received $3 \mathrm{~J} / \mathrm{cm}^{2}$ irradiation. After LED exposure, cells in different plate were respectively incubated in DMEM with $10 \%$ fetal bovine serum for $6 \mathrm{~h}, 12 \mathrm{~h}, 18 \mathrm{~h}$, and $24 \mathrm{~h}$. After washing cells with PBS, $20 \mu \mathrm{l}$ of MTT $(5 \mathrm{mg} / \mathrm{mL}$ in DMEM media) was added to each well and incubated for $4 \mathrm{~h}$, then $100 \mu \mathrm{l}$ of triplex solution $(10 \%$ SDS, $5 \%$ isobutanol, and $12 \mu \mathrm{M} \mathrm{HCl}$ ) was added into each well and incubated at $37^{\circ} \mathrm{C}$ for $12 \mathrm{~h}$. A microplate reader was used to measure the absorbance values (OD) at $490 \mathrm{~nm}$. Five replicate wells were set for each group.

\section{Annexin V-propidium iodide (PI) staining for apoptosis/necrosis detection by flow cytometry}

The cells at $6 \mathrm{~h}$ after different treatments were gently trypsinized, washed in cold PBS and re-suspended in $500 \mu \mathrm{L}$ binding buffer. Then, cells were incubated with $5 \mu \mathrm{L} /$ tube Annexin V-FITC for 15 min at $25^{\circ} \mathrm{C}$ in the dark, and $5 \mu \mathrm{L} /$ tube PI was added. Samples were analyzed using a flow cytometer. The early apoptotic cells, late apoptotic cells and the necrotic cells were estimated as the percentage of the total number of cells by BD FACSDiva 7.0 software.

\section{RNA extraction and quantitative real-time PCR}

The cells at $3 \mathrm{~h}$ after HB-LED PDT treatment were used for mRNA analysis. Total RNA was extracted 
from KFB cells using the Trizol method. Three $\mu \mathrm{g}$ of RNA were reverse-transcribed to cDNA as the PCR template. The primers used in the experiment are listed as following [11]:

$B A X \mathrm{fw}$ : ACTGGACAGTAACATGGAGCTG, $B A X$ rev: AGCCCATGATGGTTCTGATCAG, $B C L-2 \mathrm{fw}$ : TGGATGACTGAGTACCTGAACCG, $B C L-2$ rev: TGAGCAGAGTCTTCAGAGACAGC, GAPDH fw: TGAGTACGTCGTGGAGTCCACTG, GAPDH rev: GGTGCTAAGCAGTTGGTGGTG.

Real-time PCR conditions include: initial denaturation at $95^{\circ} \mathrm{C}$ for $8 \mathrm{~min}$, then $95^{\circ} \mathrm{C}$ for $15 \mathrm{~s}, 59^{\circ} \mathrm{C}$ for $20 \mathrm{~s}, 72^{\circ} \mathrm{C}$ for $30 \mathrm{~s}$ and total of 45 cycles. Each sample was analyzed in triplicate. Specificity of the amplified products was verified by melting curve analysis (Supplementary Fig. 2a, b). The mRNA expression levels of target genes were normalized to GAPDH from the same cDNA. The relative expression levels were calculated using the $\Delta \Delta \mathrm{Ct}$ method.

\section{BAX and BCL-2 detection by intracellular staining}

Flow cytometry intracellular staining has been used to detect BAX and BCL-2. The cells at 3.5h after different treatments were trypsinized and centrifuged at $1500 \mathrm{rpm}$ for $5 \mathrm{~min}$. Precipitated cells were washed twice with PBS and fixed with 1mL BioLegend's fixation buffer at room temperature in the dark for 15 min. After centrifugation and discarding the supernatant, cells were resuspended in $300 \mu \mathrm{L}$ permeabilization buffer. Five $\mu \mathrm{L}$ of FITC-conjugated anti-BAX or PE-conjugated anti-BCL-2 was added to tube respectively and incubated at $4^{\circ} \mathrm{C}$ in the dark for $45 \mathrm{~min}$. FITC-conjugated mouse IgG1 and PE-conjugated mouse IgG1 were used as isotype controls. Samples were finally resuspended in $500 \mu \mathrm{L}$ permeabilization buffer after twice quick washing with permeabilization buffer and analyzed by flow cytometry [12-14]. The amount of protein was estimated through calculating median fluorescence intensity (MFI) by FlowJo 10.0.7.

\section{Measurement of intracellular free $\mathrm{Ca}^{2+}$ with Fluo-3/AM}

The intracellular $\mathrm{Ca}^{2+}$ was detected using the $\mathrm{Ca}^{2+}$-sensitive fluorescent indicator, Fluo-3 [15]. The cells grown on glass coverslips were treated with HB-LED PDT. Fluo-3/AM ( $5 \mu \mathrm{mol} / \mathrm{L})$ in $\mathrm{Ca}^{2+}$-free PBS buffer was loaded on cells at $4 \mathrm{~h}$ after HB-LED PDT treatment and incubated at $37^{\circ} \mathrm{C}$ for $30 \mathrm{~min}$. After washing twice with PBS, cell fluorescence was detected using a confocal laser-scanning microscope at $488 \mathrm{~nm}$ for excitation and $530 \mathrm{~nm}$ for emission. $\mathrm{Ca}^{2+}$ levels were presented by mean fluorescence intensity
(MFI) of the cells. MFI was obtained using the instrument software (Imaging Software for Microscopy).

\section{Caspase- 3 activity assay}

The activity of caspase- 3 was examined using the caspase- 3 activity kit [16]. The assay is based on the detection of the yellow $p$-nitronanilide ( $p \mathrm{NA})$. $p \mathrm{NA}$ is a cleavage from acetyl-Asp-Glu-Val-Asp $p$-nitroanilide (Ac-DEVD- $p \mathrm{NA}$ ), the substrate of caspase-3. Briefly, cells were trypsinized at $5 \mathrm{~h}$ after different treatment. Trypsinized cells were washed with PBS and incubated in lysis buffer on ice for 15 min. After centrifugation at $13,000 \mathrm{~g}$ for $20 \mathrm{~min}$ at $4^{\circ} \mathrm{C}$, the supernatant was incubated with Ac-DEVD- $p$ NA in 96-well plates at $37^{\circ} \mathrm{C}$ for $2 \mathrm{~h}$. Samples were measured with a microplate reader at an absorbance of $405 \mathrm{~nm}$.

\section{Statistical analysis}

SPSS 22.0 was used for statistical analysis. The results were expressed as mean $\pm S D$. Data was tested by one-way ANOVA, and LSD test was used for multiple comparisons. $\mathrm{P}<0.05$ was considered to be statistically significant. All experiments were repeated at least 3 times.

\section{Results}

\section{Effect of HB-LED PDT on the viability of KFB}

To determine the best time point for cell apoptosis analysis, we performed MTT assay to evaluate the effects of HB-LED PDT on the viability of KFB cells. Based on our preliminary experiments, $3 \mathrm{~J} / \mathrm{cm}^{2}$ LED yellow light and $10^{-7} \mathrm{~mol} / \mathrm{L} \mathrm{HB}$ were chosen to treat KFB in vitro. Cell viability determined by MTT assay at different time points is shown in Figure 1. In comparison to the negative control group (NC), HB alone, LED alone and HB-LED treatment reduced KFB viability, but HB-LED PDT had the highest impact on cell viability (Fig 1). Importantly, the most significant reduction of cell viability occurred at $12 \mathrm{~h}$ after treatment. At this time point, MTT assay showed that LED alone caused a $16.57 \%$ $(\mathrm{P}<0.001)$ reduction and $\mathrm{HB}$ alone resulted in $25.77 \%$ $(\mathrm{P}<0.001)$ reduction of cell activity, but HB-LED PDT significantly decreased cell activity by $50.23 \%$ $(\mathrm{P}<0.001)$ compared to NC cells (Fig 1). These results provided the basis for other experiments including cell apoptosis and mechanism analysis at or before $6 \mathrm{~h}$ following PDT treatment.

\section{HB-LED PDT induces cell apoptosis}

Apoptosis was assessed by Annexin V/PI double staining with a flow cytometer. Representative flow charts from one measurement are shown in 
figure 2 (Fig 2a). In the flow charts, the cells in the upper left, lower left, lower right and upper right quadrant respectively represent necrotic cells, normal live cells, early apoptotic cells, and late apoptotic cells. Few necrotic cells were seen in any treatment groups. However, HB-LED PDT treatment caused most cells to undergo apoptosis, and most cells were in the late apoptotic stage while a considerable amount were in early apoptosis (Fig 2a). By quantification from three different experiments, the total apoptosis rate (early plus late apoptotic cells) amounted to $57.30 \%$ $(\mathrm{P}<0.001)$ in the HB-LED PDT group (Fig 2b). HB alone caused apoptosis in $25.77 \%(\mathrm{P}<0.001)$ of the cells and LED alone only slightly induced apoptosis compared to NC (Fig 2b). The data indicates that HB and LED are synergistic in promoting KFB apoptosis rather than simply additive.

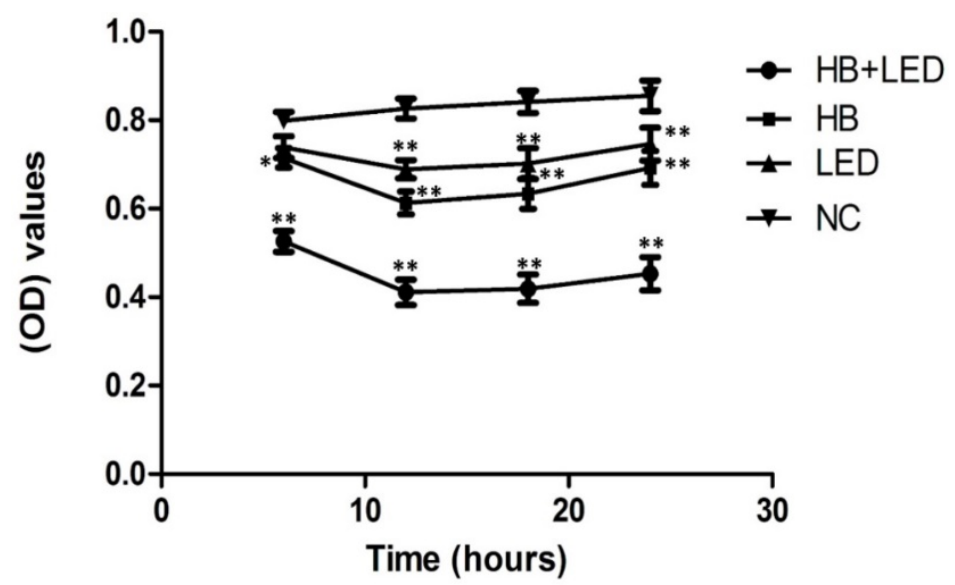

Figure 1. Analysis of KFB viability at different time points upon the treatment of HB, LED and HB-LED PDT. Significant reduction of cell viability occurred at $12 \mathrm{~h}$ after treatment. At this time point, MTT assay showed that LED alone caused a $16.57 \%$ reduction and $\mathrm{HB}$ alone resulted in $25.77 \%$ reduction of cell activity, but HB-LED PDT significantly decreased the cell activity by $50.23 \%$ compared to NC cells. $* P<0.05$, $* * P<0.001$.

a

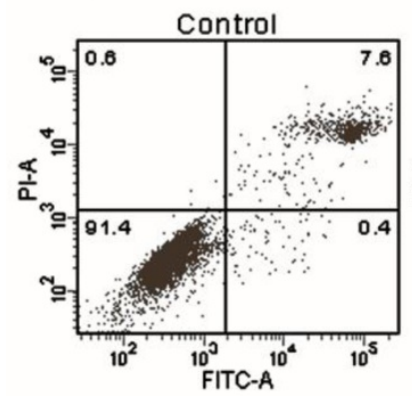

$\mathrm{HB}$

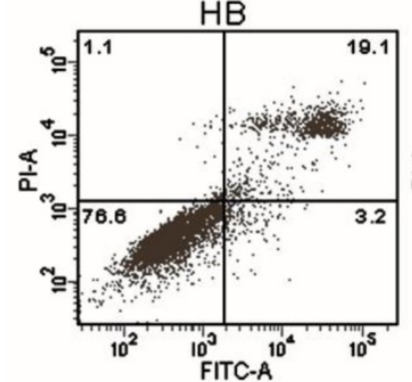

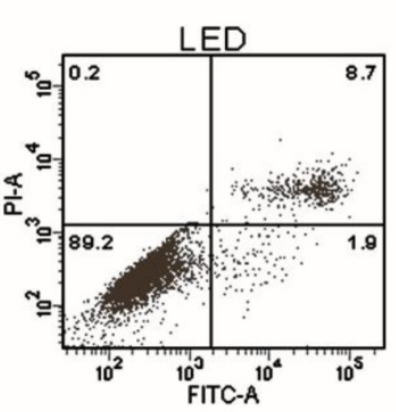

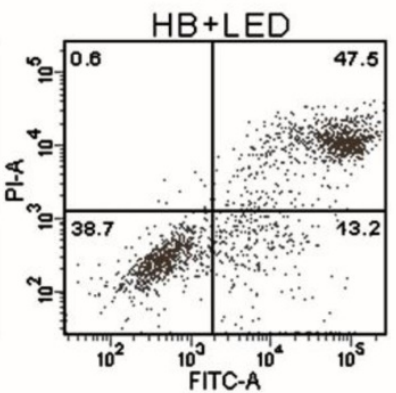

b

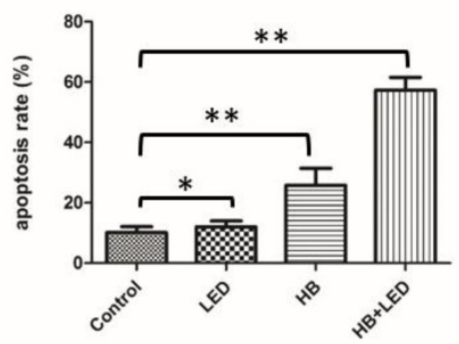

Figure 2. Analysis of apoptosis upon the treatment of HB, LED and HB-LED PDT. AnnexinV/PI double staining with flow cytometry analysis was used to examine the apoptosis. (a) The typical flow chart from one measurement at $6 \mathrm{~h}$ after different treatments showing that HB-LED PDT treatment caused most apoptotic cells (lower right and upper right quadrant), but few necrotic cells (upper left quadrant). (b) Average result from three different experiments showed that total apoptosis rate (early apoptotic plus late apoptotic) amounted to $57.30 \%, 25.77 \%$ and $11.93 \%$ by the treatment of HB-LED, HB, and LED respectively. $* P<0.05$, $* * P<0.001$. 
a

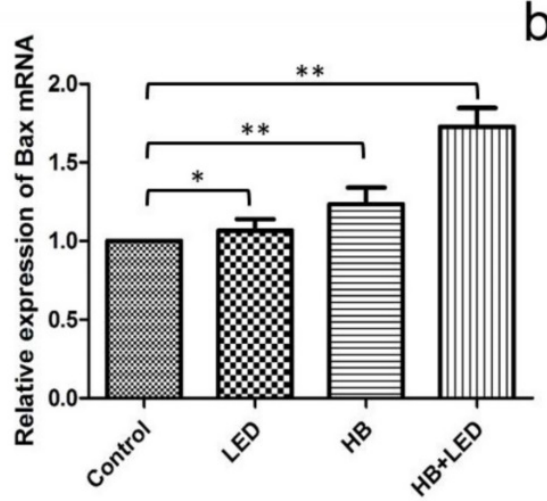

C

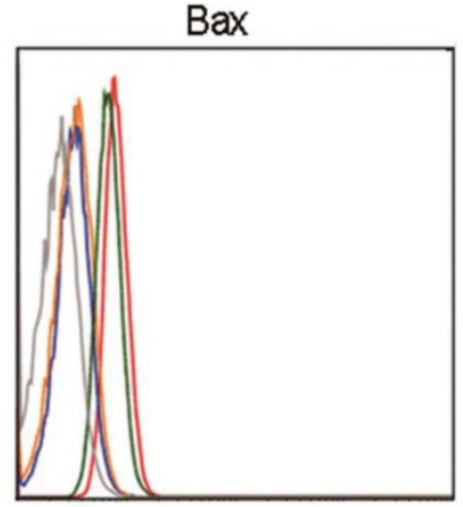

d

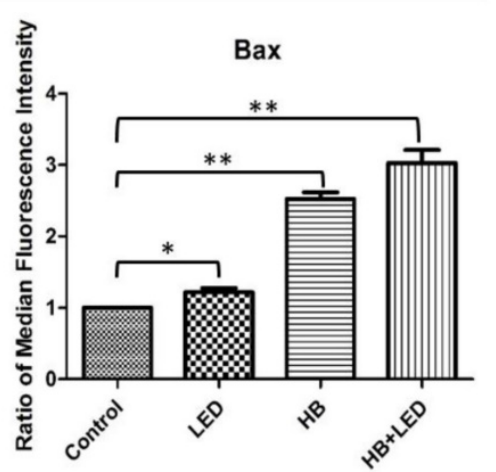

b

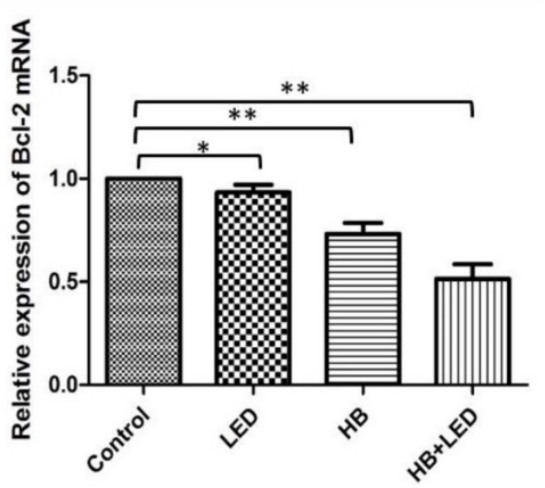

$\mathrm{Bcl}-2$

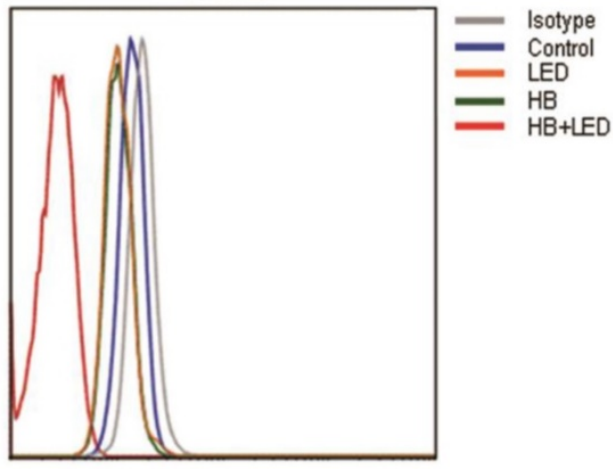

e

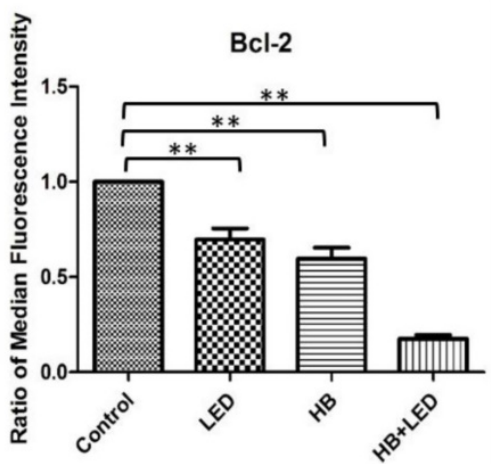

Figure 3. Analysis of $B A X$ and $B C L-2$ mRNA and protein expression upon the treatment of HB, LED and HB-LED PDT. mRNA expression was analyzed by real-time PCR $(\mathrm{a}, \mathrm{b})$ and protein expression was examined using flow cytometry intracellular staining (c-d). (a) Compared to NC, BAX mRNA in HB-LED PDT, HB, and LED groups increased by $72.67 \%, 23.33 \%$, and $6.67 \%$, respectively. (b) In comparison with NC, mRNA of BCL-2 decreased by $48.57 \%, 26.77 \%$ and $6.73 \%$ in HB-LED, HB and LED groups, respectively. (c) The histogram of flow cytometry intracellular staining, in which the right-shift of the peak position represents an increase of protein and the left-shift of peak position indicates a decrease of protein expression. Compared to isotype control, the peak position of BAX was observed in most right and BCL-2 was observed in far left in the histogram at 5 after HB-LED PDT treatment. (d) By calculation of median fluorescence intensity (MFI), BAX protein expression in HB-LED PDT group increased by 3.03-fold in comparison with NC. (e) By calculation of MFI, BCL-2 protein expression in HB-LED PDT group was reduced to $17.50 \%$ of $N C$ group. $* P<0.05$, $* * P<0.001$.

\section{HB-LED PDT upregulates BAX and downregulates BCL-2 expression}

The BCL-2 family plays an important role in the regulation of apoptosis $[17,18]$. The $B C L-2$ gene encodes a protein that blocks cell apoptosis, while $B A X$ promotes apoptosis. To explore whether such a mechanism is involved in KFB apoptosis induced by HB-LED PDT, the mRNA levels of $B A X$ and $B C L-2$ were examined. BAX mRNA in the HB-LED PDT, HB, LED groups increased by $72.67 \%(\mathrm{P}<0.001), 23.33 \%$
$(\mathrm{P}<0.001)$, and $6.67 \% \quad(\mathrm{P}<0.05)$ respectively, in comparison to $B A X$ gene expression in NC (Fig $3 a$ ). In contrast, mRNA of $B C L-2$ in the HB-LED PDT, HB alone and LED alone group decreased by $48.57 \%$ $(\mathrm{P}<0.001), 26.77 \% \quad(\mathrm{P}<0.001)$ and $6.73 \% \quad(\mathrm{P}<0.05)$, respectively (Fig $3 \mathrm{~b}$ ). These observations suggest that the $B A X$ gene expression was upregulated but $B C L-2$ was downregulated by HB-LED PDT treatment.

In order to detect the protein levels of BAX and BCL-2 in KFB, we performed flow cytometry 
intracellular staining. The result showed that BAX protein levels were significantly increased and BCL-2 protein levels were dramatically decreased in KFB cells after treatments (Fig 3c). Specifically, BAX in the HB-LED PDT group increased by 3.03 -fold $(\mathrm{P}<0.001)$ compared to NC (Fig 3d), BCL-2 in the HB-LED PDT group was conversely reduced to $17.50 \%(\mathrm{P}<0.001)$ of

a

b

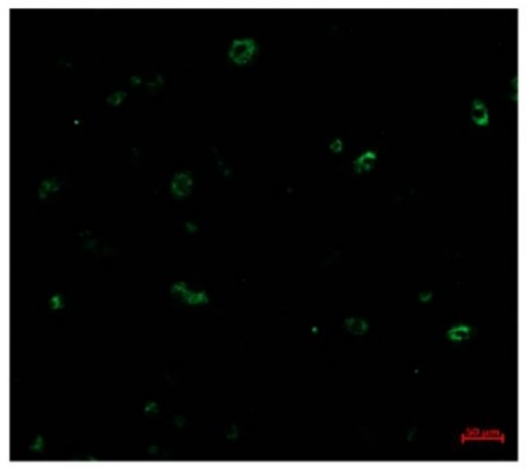

C

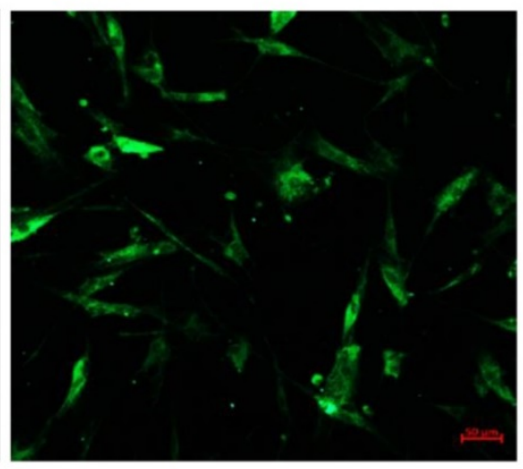

d

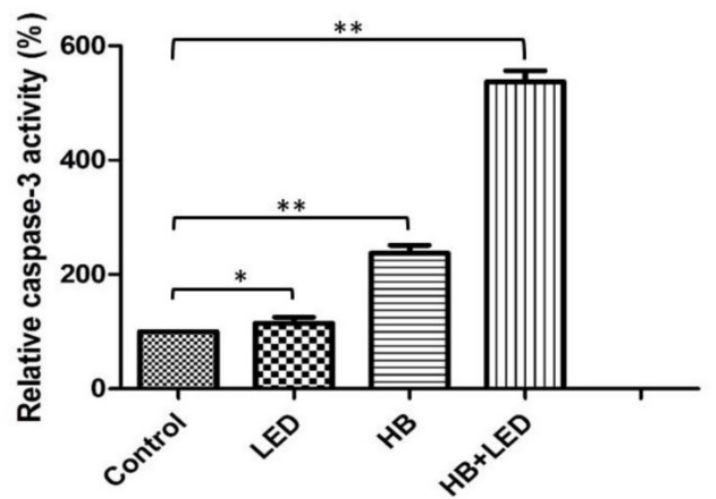

Figure 4. Analysis of intracellular free $\mathrm{Ca}^{2+}$ level and caspase-3 activity upon the treatment of HB-LED PDT. Confocal laser microscopy was used to detect the intracellular free $\mathrm{Ca}^{2+}$ level (a-c) and ELISA kit was used to examine the caspase-3 activity (d). (a) The mean fluorescence intensity (MFI) showing that the intracellular free $\mathrm{Ca}^{2+}$ in cells of HB-LED PDT group increased by 3.77-fold compared to NC at 2 hours after treatment of KFB cells. (b) Confocal laser microscopy image showing low Fluo-3 fluorescence around the nucleus in NC. (c) Confocal laser microscopy showed high Fluo-3 fluorescence intensity spreading in the cytoplasm of HB-LED PDT treated cells. (d) Compared to NC, the activity of caspase-3 was increased by $5.37,2.37$ and 1.15 times in HB-LED PDT, HB, and LED group, respectively. $* P<0.05$, $* * P<0.001$. the NC group (Fig 3e). Overall, the BAX/BCL-2 ratio increased from 0.1766 in NC to 3.0238 in the HB-LED PDT group. Similar trends occurred in the HB alone and LED alone groups, although their changes were less than that of HB-LED PDT treated cells. Since an increase in the ratio of $\mathrm{BAX} / \mathrm{BCL}-2$ can trigger apoptosis, the current data implicates BAX and BCL-2 in apoptosis induced by HB-LED PDT.

\section{HB-LED PDT increases the levels of intracellular free $\mathrm{Ca}^{2+}$ and caspase- 3 activity}

Because increases in intracellular calcium levels and caspase- 3 activation have been reported to play crucial roles in cell apoptosis [19-22], we further examined the changes of intracellular free $\mathrm{Ca}^{2+}$ level and caspase- 3 activity in KFB in response to HB-LED PDT treatment. By confocal laser microscopy analysis, HB-LED PDT treatment significantly increased intracellular free $\mathrm{Ca}^{2+}$ in KFB cells by 3.77-fold $(\mathrm{P}<0.001)$ compared to that in NC cells (Fig 4a-c). Using caspase- 3 activity assay kit analysis, we showed that HB-LED PDT significantly increased the activity of caspase- 3 by 5.37 -fold compared to NC $(\mathrm{P}<0.001)$ (Fig 4d). HB alone and LED alone raised caspase-3 activity by 2.37-fold $\quad(\mathrm{P}<0.001) \quad$ and 1.15 -fold $(\mathrm{P}<0.05)$, respectively (Fig $4 \mathrm{~d})$. These results indicate that intracellular free $\mathrm{Ca}^{2+}$ elevation and the activation of caspase-3 are involved in the HB-LED PDT-induced KFB apoptosis.

\section{Discussion}

Targeting the inhibition of hyperproliferative fibroblasts may lead to novel therapeutic methods for keloid and other fibrotic diseases. In this study, we showed that HB plus LED yellow light significantly promoted cell apoptosis and reduced cell viability. HB has high absorption at wavelength of $470 \mathrm{~nm}$, but also has considerable absorption at $585 \mathrm{~nm}$ or $630 \mathrm{~nm}$ wavelength possibly due to the difference of solvents $[9,23]$. Considering that major pathological changes of keloid are in the dermis and based on the absorption spectrum of HB (Supplementary Fig. 1) determined in our preliminary experiment, yellow 
light from light-emitting diode, which has considerable penetration of skin, [24] was chosen in current study. Analysis from the rest of our experiments showed that LED light alone had lesser effects on KFB.

The BCL-2 family by composition of BCL-2 protein and its homologues plays an essential role in the regulation of cell death and cell survival [25]. The balance of proapoptotic to antiapoptotic proteins maintains cell homeostasis and BAX has been suggested to regulate the critical balance between cellular life and death [22, 26]. In this study, we demonstrated that HB-LED PDT treatment significantly downregulated BCL-2 and dramatically upregulated BAX at both mRNA and protein level. In particular, a sensitive and quantitative flow cytometry intracellular staining was used to analyze the target protein [27-29], and showed that BAX/BCL-2 protein ratio increased from 0.1766 in NC cells to 3.0238 in the HB-LED PDT treated cells. The results supported the conception that increase in the BAX/BCL-2 ratio triggers initiation of apoptosis [30].

Recent studies indicated that intracellular free $\mathrm{Ca}^{2+}$ plays crucial role in controlling cell survival and death. Basal cytosolic $\mathrm{Ca}^{2+}$ drives mitochondrial bioenergetics and is essential for cell survival. Sustained $\mathrm{Ca}^{2+}$ elevation in cytoplasm in response to various stimulations induces apoptosis by damaging mitochondria [25, 31]. To further investigate the mechanism of HB-LED PDT, we measured the levels of intracellular free $\mathrm{Ca}^{2+}$. In comparison with $\mathrm{NC}$ cells, intracellular free $\mathrm{Ca}^{2+}$ in KFB at $4 \mathrm{~h}$ after HB-LED PDT treatment increased by 3.77-fold. Previous evidence showed that BCL-2 inhibited but BAX enhanced endoplasmic reticulum (ER)- $\mathrm{Ca}^{2+}$ release through interaction with inositol 1,4,5-trisphosphate (IP3) receptor $\mathrm{Ca}^{2+}$ channels on the ER $[25,31]$, therefore we postulated that the reduction in BCL-2 and increase in BAX caused by HB-LED PDT contributed to intracellular free $\mathrm{Ca}^{2+}$ elevation by releasing $\mathrm{Ca}^{2+}$ from the ER into cytoplasm. With cytosolic $\mathrm{Ca}^{2+}$ elevation, $\mathrm{BAX}$ promotes $\mathrm{Ca}^{2+}$ uptake by the mitochondrion that eventually releases cytochrome $\mathrm{C}$, activates caspase- 3 and induces cell apoptosis [25, 31]. However, since fat-soluble HB is widely distributed in the cell and can cause photodamage of the cell membrane and intracellular organelle membranes [32], it cannot be excluded that intracellular free $\mathrm{Ca}^{2+}$ elevation might also be due to increased extracellular $\mathrm{Ca}^{2+}$ entry [25].

We also showed that the activated caspase- 3 was significantly increased in KFB treated with HB-LED PDT. Caspase- 3 is the executioner caspase to degrade cellular components and thus plays a crucial role in apoptosis. Previous reports showed that increases in caspase-3 activity is crucial for keloid fibroblast apoptosis induced by serum deprivation or staurosporine in vitro [21,33]. In our experiments, we found that HB-LED PDT increased the activity of caspase-3 in KFB over five-fold compared to control KFB. Coupled with the findings of intracellular free $\mathrm{Ca}^{2+}$ elevation and alteration of the BAX/BCL-2 ratio, the results indicate that activation of caspase- 3 was through BCL-2-mitochondrial apoptotic pathways [34].

Finally, we want to mention that HB-LED PDT under conditions presented in our study caused cell death primarily through the apoptotic pathway. However, by increasing the doses of $\mathrm{HB}$ and LED PDT, HB-LED PDT resulted in cell death by necrosis (Supplementary Fig. 3). The underlying mechanism may be due to the subcellular structural damage of target cells caused by free radicals, reactive oxygen species and singlet oxygens produced by photodynamic therapy $[20,35]$. In addition, although we have not perform the experiments on the synthesis and decomposition of collagen fibers, a recent study by another group indicated that photodynamic therapy with $\mathrm{HB}$ caused the degradation of pyridinoline (PYD) cross-links in collagen [36].

Collectively, our in vitro experiments demonstrated that HB-LED PDT can effectively induce apoptosis of human keloid fibroblasts through the mitochondrial apoptotic pathway. Yellow light used in the experiment can penetrate to the deep dermis with little damage to the skin. Therefore, our current study, together with other reports that photodynamic therapy with $\mathrm{HB}$ degraded collagen [36], provided valuable evidence to further explore the therapeutic effects of HB-LED PDT for keloid or other fibrotic skin diseases.

\section{Supplementary Material}

Supplementary figures.

http://www.ijbs.com/v13p0319s1.pdf

\section{Abbreviations}

PDT: photodynamic therapy; HB: Hypocrellin B; KFB: keloid fibroblasts; LED: light-emitting diode; MTT: Methylthiazolyldiphenyl-tetrazolium bromide; AV: AnnexinV-FITC; PI: propidium iodide; FITC: fluoresceine isothiocyanate; PE: phycoerythrin; ER: endoplasmic reticulum; MFI: mean fluorescence intensity.

\section{Acknowledgments}

This work was supported by the National Natural Science Foundation of China (No. 81472903) to Gangwen Han. Guo Wei is currently supported by the Shandong Natural Science Foundation (No. ZR2014HM030). The authors thank Sha Wan, Yang 
Jiang, Xi Tan, Cao Shun, Yongsheng He, Chuanyou Xia, Fan Yang, and Yuanyuan Ju for technical support. The authors also thank Zheyi Han for proofreading the manuscript.

\section{Competing Interests}

declare.

The authors have no conflicts of interest to

\section{References}

1. Jurzak M, Adamczyk K, Antonczak P, Garncarczyk A, Kusmierz D, Latocha M. Evaluation of genistein ability to modulate CTGF mRNA/protein expression, genes expression of TGFbeta isoforms and expression of selected genes regulating cell cycle in keloid fibroblasts in vitro. Acta poloniae pharmaceutica. 2014; 71: 972-86.

2. Russell SB, Russell JD, Trupin KM, Gayden AE, Opalenik SR, Nanney LB, et al. Epigenetically altered wound healing in keloid fibroblasts. The Journal of investigative dermatology. 2010; 130: 2489-96.

3. Gauglitz GG, Korting HC, Pavicic T, Ruzicka T, Jeschke MG. Hypertrophic scarring and keloids: pathomechanisms and current and emerging treatment strategies. Mol Med. 2011; 17: 113-25.

4. McKeown SR, Hatfield P, Prestwich RJ, Shaffer RE, Taylor RE. Radiotherapy for benign disease; assessing the risk of radiation-induced cancer following exposure to intermediate dose radiation. The British journal of radiology. 2015; 88: 20150405.

5. Wan X, Chen Y. Hypocrellin A-a new drug for photochemotherapy. Chin sci bull. 1981;26: 1040-42.

6. Chang JE, Cho HJ, Yi E, Kim DD, Jheon S. Hypocrellin B and paclitaxel-encapsulated hyaluronic acid-ceramide nanoparticles for targeted photodynamic therapy in lung cancer. Journal of photochemistry and photobiology B, Biology. 2016; 158: 113-21.

7. Jiang Y, Leung AW, Wang X, Zhang H, Xu C. Effect of photodynamic therapy with hypocrellin B on apoptosis, adhesion, and migration of cancer cells. International journal of radiation biology. 2014; 90: 575-9.

8. Ma J, Jiang L. Photogeneration of singlet oxygen (1O2) and free radicals (Sen*-, $\mathrm{O}^{*}{ }^{*}$ ) by tetra-brominated hypocrellin B derivative. Free radical research. 2001; 35: 767-77.

9. Zhao H, Yin R, Chen D, Ren J, Wang Y, Zhanga J, et al. In vitro and in vivo antitumor activity of a novel hypocrellin B derivative for photodynamic therapy. Photodiagnosis and photodynamic therapy. 2014; 11: 204-12.

10. Chen T, Wang C, Liu Q, Meng Q, Sun H, Huo X, et al. Dasatinib reverses the multidrug resistance of breast cancer MCF-7 cells to doxorubicin by downregulating P-gp expression via inhibiting the activation of ERK signaling pathway. Cancer biology \& therapy. 2015; 16: 106-14.

11. Honisch S, Yu W, Liu G, Alesutan I, Towhid ST, Tsapara A, et al. Chorein addiction in VPS13A overexpressing rhabdomyosarcoma cells. Oncotarget. 2015; 6: 10309-19.

12. Al Khatib S, Keles S, Garcia-Lloret M, Karakoc-Aydiner E, Reisli I, Artac H, et al. Defects along the $\mathrm{T}(\mathrm{H}) 17$ differentiation pathway underlie genetically distinct forms of the hyper IgE syndrome. The Journal of allergy and clinical immunology. 2009; 124: 342-8, 8 e1-5.

13. Dunkle A, Dzhagalov I, He YW. Cytokine-dependent and cytokine-independent roles for Mcl-1: genetic evidence for multiple mechanisms by which Mcl-1 promotes survival in primary $\mathrm{T}$ lymphocytes. Cell death \& disease. 2011; 2: e214.

14. Kon OM, Sihra BS, Till SJ, Corrigan CJ, Kay AB, Grant JA. Unstimulated basophils in atopic and nonatopic subjects express intracellular interleukin-4: detection by flow cytometry. Allergy. 1998; 53: 891-6.

15. Xu SY, Hu YF, Li WP, Wu YM, Ji Z, Wang SN, et al. Intermittent hypothermia is neuroprotective in an in vitro model of ischemic stroke. International journal of biological sciences. 2014; 10: 873-81.

16. Liu C, Yu K, Shi X, Wang J, Lam PK, Wu RS, et al. Induction of oxidative stress and apoptosis by PFOS and PFOA in primary cultured hepatocytes of freshwater tilapia (Oreochromis niloticus). Aquat Toxicol. 2007; 82: 135-43.

17. Aliparasti MR, Alipour MR, Almasi S, Feizi H. Ghrelin Administration Increases the Bax/Bcl-2 Gene Expression Ratio in the Heart of Chronic Hypoxic Rats. Advanced pharmaceutical bulletin. 2015; 5: 195-9.

18. Zhu AK, Zhou H, Xia JZ, Jin HC, Wang K, Yan J, et al. Ziyuglycoside II-induced apoptosis in human gastric carcinoma BGC-823 cells by regulating Bax/Bcl-2 expression and activating caspase-3 pathway. Brazilian journal of medical and biological research $=$ Revista brasileira de pesquisas medicas $\mathrm{e}$ biologicas / Sociedade Brasileira de Biofisica [et al]. 2013; 46: 670-5.

19. Castano AP, Demidova TN, Hamblin MR. Mechanisms in photodynamic therapy: part two-cellular signaling, cell metabolism and modes of cell death. Photodiagnosis and photodynamic therapy. 2005; 2: 1-23.

20. Pan Z, Avila A, Gollahon L. Paclitaxel induces apoptosis in breast cancer cells through different calcium--regulating mechanisms depending on external calcium conditions. International journal of molecular sciences. 2014; 15: 2672-94.
21. Akasaka $Y$, Ishikawa $Y$, Ono I, Fujita $K$, Masuda T, Asuwa N, et al. Enhanced expression of caspase- 3 in hypertrophic scars and keloid: induction of caspase-3 and apoptosis in keloid fibroblasts in vitro. Laboratory investigation; a journal of technical methods and pathology. 2000; 80: 345-57.

22. Kelly PN, Strasser A. The role of Bcl-2 and its pro-survival relatives in tumourigenesis and cancer therapy. Cell death and differentiation. 2011; 18: 1414-24.

23. Estey EP, Brown K, Diwu Z, Liu J, Lown JW, Miller GG, et al. Hypocrellins as photosensitizers for photodynamic therapy: a screening evaluation and pharmacokinetic study. Cancer chemotherapy and pharmacology. 1996; 37: 343-50.

24. Blank M, Kostenich G, Lavie G, Kimel S, Keisari Y, Orenstein A. Wavelength-dependent properties of photodynamic therapy using hypericin in vitro and in an animal model. Photochemistry and photobiology. 2002; 76: 335-40.

25. Rong Y, Distelhorst CW. Bcl-2 protein family members: versatile regulators of calcium signaling in cell survival and apoptosis. Annual review of physiology. 2008; 70: 73-91.

26. Walensky LD, Gavathiotis E. BAX unleashed: the biochemical transformation of an inactive cytosolic monomer into a toxic mitochondrial pore. Trends in biochemical sciences. 2011; 36: 642-52.

27. Fujisaki J, Wu J, Carlson AL, Silberstein L, Putheti P, Larocca R, et al. In vivo imaging of Treg cells providing immune privilege to the haematopoietic stem-cell niche. Nature. 2011; 474: 216-9.

28. Zamai L, Canonico B, Gritzapis A, Luchetti F, Felici C, Della Felice M, et al. Intracellular detection of $\mathrm{Bcl}-2$ and p53 proteins by flow cytometry: comparison of monoclonal antibodies and sample preparation protocols. Journal of biological regulators and homeostatic agents. 2002; 16: 289-302.

29. Millard I, Degrave E, Philippe M, Gala JL. Detection of intracellular antigens by flow cytometry: comparison of two chemical methods and microwave heating. Clinical chemistry. 1998; 44: 2320-30.

30. Mroz P, Yaroslavsky A, Kharkwal GB, Hamblin MR. Cell death pathways in photodynamic therapy of cancer. Cancers. 2011; 3: 2516-39.

31. La Rovere RM, Roest G, Bultynck G, Parys JB. Intracellular $\mathrm{Ca}(2+)$ signaling and $\mathrm{Ca}(2+)$ microdomains in the control of cell survival, apoptosis and autophagy. Cell calcium. 2016; 60: 74-87.

32. Ding HY. Apoptotic and Necrotic Cell Death Studies of Hypocrellins for Photodynamic Therapy. Chinese Journal of Laser Medicine \& Surgery. 2007; 16: 320-4.

33. Nakazono-Kusaba A, Takahashi-Yanaga F, Morimoto S, Furue M, Sasaguri T. Staurosporine-induced cleavage of alpha-smooth muscle actin during myofibroblast apoptosis. The Journal of investigative dermatology. 2002; 119: 1008-13.

34. Shalini S, Dorstyn L, Dawar S, Kumar S. Old, new and emerging functions of caspases. Cell death and differentiation. 2015; 22: 526-39.

35. Castano AP, Demidova TN, Hamblin MR. Mechanisms in photodynamic therapy: part one-photosensitizers, photochemistry and cellular localization. Photodiagnosis and photodynamic therapy. 2004; 1: 279-93.

36. Yan H, Chen Y, Zhang J, Liu W, Chen R. The Role of Free Radicals in the Photodynamic Treatment of Fibrotic Skin Diseases. Advances in experimental medicine and biology. 2016; 923: 69-74. 